\title{
Transient response of thermocapillary pumping of a droplet in a micro heat engine
}

\author{
A. Odukoya ${ }^{1}$ and G. F. Naterer ${ }^{2}$ \\ 1, 2 University of Ontario Institute of Technology, Oshawa, Ontario, Canada
}

\begin{abstract}
A new analytical model is developed to predict the transient velocity and voltage gnerated due to thermocapillary pumping in a micro heat engine (MHE). Modeling, fabrication, and experimental studies of the MHE are presented in this paper. The fabrication technique uses lead zirconate titanate (PZT) as a substrate for the MHE. Analytical and experimental results are reported for Ti-W microheaters that transfer heat to the thermocapillary motion. The effect of surface roughness on thermocapillary motion of the droplet in the MHE is examined. The results show that a higher bulk droplet velocity reduces the effect of surface roughness on the displacement of the droplet. The analytical model of the efficiency of the system considers the electromechanical coupling factor and frictional irreversibilities to yield about $1.6 \%$ efficiency with a maximum voltage of $1.25 \mathrm{mV}$ for the range of displacement considered in this study.
\end{abstract}

\section{Nomenclature}
A cross sectional area $\left(\mathrm{m}^{2}\right)$
b width of membrane (m)
$\mathrm{C}_{\mathrm{p}} \quad$ specific heat $(\mathrm{J} / \mathrm{kgK})$
$D_{\mathrm{ij}} \quad$ electrical polarization $\left(\mathrm{C} / \mathrm{m}^{2}\right)$
$\mathrm{d}_{\mathrm{ij}} \quad$ piezoelectric coefficient $(\mathrm{C} / \mathrm{N})$

\footnotetext{
1 Research Project Engineer, Faculty of Engineering and Applied Science, Memorial University, St. John's, Newfoundland, 240 Prince Phillip Drive, St. John’s, NL Canada A1B 3X5

${ }^{2}$ Dean, Faculty of Engineering and Applied Science, Memorial University, St. John's, Newfoundland, 240 Prince Phillip Drive, St. John’s, NL Canada A1B 3X5
} 


\begin{tabular}{|c|c|}
\hline $\mathrm{E}$ & Young's modulus of elasticity $\left(\mathrm{N} / \mathrm{m}^{2}\right)$ \\
\hline$e_{v}$ & uncertainty in voltage measurement $(\mathrm{V})$ \\
\hline$e_{i}$ & uncertainty in current measurement (A) \\
\hline $\mathrm{F}$ & force $(\mathrm{N})$ \\
\hline G & geometry constant \\
\hline $\mathrm{G}_{\mathrm{f}}$ & leverage factor \\
\hline $\mathrm{H}$ & fixed height (m) \\
\hline I & current $(\mathrm{mA}, \mathrm{A})$ \\
\hline K & roughness height (m) \\
\hline $\mathrm{K}_{\mathrm{b}}$ & bending modulus \\
\hline $\mathrm{k}_{\mathrm{p}}$ & coupling coefficient \\
\hline $\mathrm{L}$ & length (m) \\
\hline $\mathrm{m}$ & mass (kg) \\
\hline $\mathrm{n}$ & empirical corelation constant \\
\hline $\mathrm{P}$ & pressure $(\mathrm{kPa})$ \\
\hline $\mathrm{P}_{\mathrm{i}}$ & power (W) \\
\hline$P_{\varsigma}$ & Poiseuille number \\
\hline$Q_{f}$ & quality factor \\
\hline$r$ & electrical resistance $(\mathrm{k} \Omega$ ) \\
\hline$R$ & gas constant (J/kgK) \\
\hline $\operatorname{Re}$ & Reynolds number \\
\hline
\end{tabular}




\begin{tabular}{|c|c|}
\hline$t$ & time (s) \\
\hline$T$ & temperature $\left({ }^{\circ} \mathrm{C}\right.$ or $\left.\mathrm{K}\right)$ \\
\hline$T_{i j}$ & applied mechanical stress $\left(\mathrm{N} / \mathrm{m}^{2}\right)$ \\
\hline$t_{p z t}$ & thickness of membrane (m) \\
\hline$t_{\text {sub }}$ & thickness of substrate (m) \\
\hline $\mathrm{u}$ & instantaneous velocity $\left(\mathrm{m} / \mathrm{s}^{2}\right)$ \\
\hline $\mathrm{U}$ & uncertainty \\
\hline $\bar{u}$ & average velocity $\left(\mathrm{m} / \mathrm{s}^{2}\right)$ \\
\hline$u^{*}$ & dimensionless velocity \\
\hline $\mathrm{u}_{\mathrm{b}}$ & bulk velocity $\left(\mathrm{m} / \mathrm{s}^{2}\right)$ \\
\hline $\mathrm{V}$ & volume $\left(\mathrm{m}^{3}\right)$ \\
\hline $\mathrm{V}_{\mathrm{e}}$ & induced electric field $(\mathrm{V} / \mathrm{m})$ \\
\hline $\mathrm{V}_{\text {Dout }}$ & output voltage $(\mathrm{mV})$ \\
\hline $\mathrm{W}_{\mathrm{m}}$ & piezoelectric displacement (m) \\
\hline $\mathrm{x}$ & displacement (m) \\
\hline $\mathrm{Z}_{\mathrm{i}}$ & deposited material height (m) \\
\hline $\mathrm{Z}_{\mathrm{n}}$ & distance from neutral axis (m) \\
\hline
\end{tabular}

\section{Greek}
$\Delta \quad$ change
$\delta^{*} \quad$ boundary layer thickness (m) 
$\varepsilon$

$\eta$

$\gamma_{0}$

$\mu$

$\rho$

$\sigma$

$\theta$

$\zeta$

v

$\Phi$

$\psi$

$\chi$

\section{Subscripts}

$\begin{array}{ll}\text { a } & \text { air } \\ \text { app } & \text { apparent } \\ \text { d } & \text { droplet } \\ \text { i } & \text { initial } \\ \text { L } & \text { left } \\ \text { m } & \text { meniscus } \\ \text { o } & \text { start }\end{array}$


pzt lead zirconate titanate

$\begin{array}{ll}\mathrm{R} & \text { right } \\ \text { sub } & \text { substrate }\end{array}$

$\begin{array}{ll}\text { Abbreviations } \\ \text { CIRFE } & \text { Centre of Integrated Radio Frequency Engineering } \\ \text { DC } & \text { Direct Current } \\ \text { IPA } & \text { Isopropyl Alcohol } \\ \text { LOR } & \text { Lift Off Resist } \\ \text { MEMS } & \text { Microelectromechanical Systems } \\ \text { MHE } & \text { Micro Heat Engine } \\ \text { PZT } & \text { Lead Zirconate Titanate } \\ \text { RF } & \text { Radio Frequency } \\ \text { RIE } & \text { Reactive Ion Etching } \\ \text { TCP } & \text { Thermocapillary Pumping } \\ \text { Ti-W } & \text { Titanium Tungsten } \\ \text { UV } & \text { Ultra Violet }\end{array}$

\section{Introduction}

Increasing the efficiency of MEMS devices can increase their energy utilization and practical applicability. Waste heat from components in MEMS devices can be recovered to generate electricity for individual electrical components within micro devices. Waste heat recovery can be achieved by various methods of energy conversion such as thermoelectric or piezoelectric 
materials. This paper examines the effects of droplet motion on the energy conversion in MEMS devices, particularly for a micro heat engine (MHE) application involving thermocapillary pumping (TCP).

Micro heat exchangers have been used extensively for convective cooling of microelectronic circuits [1, 2]. MEMS have also been used for bio-devices to separate biological cells and perform blood analysis [3]. Near-wall flow control [4], micro engines [5], and microchannel batteries [6] are other examples of MEMS applications. A nano-motor, which operates by transferring atoms between two molten metal droplets in a carbon nanotube was developed at the University of California [7]. Researchers at the National Institute for Nanotechnology, University of Alberta, Canada, have fabricated a micro-device that produces electricity from the interaction between flowing water and the surfaces of microchannels [6]. Yang et al. [6] achieved electrical currents between $1-2 \mu \mathrm{A}$, by flowing water through a glass filter containing millions of microchannels across a $30 \mathrm{~cm}$ hydrostatic pressure drop. Researchers at Oregon State University, Washington State University and the US Army Research Laboratory have developed a novel energy source called the $\mathrm{P}^{3}$ micro heat engine [5]. An external heat source is used to generate phase change and increase the vapor fraction of a saturated liquid-vapor mixture in a chamber. The expansion process flexes a piezoelectric membrane to generate an output voltage.

This paper examines an new method of microfluidic electricity generation based on thermocapillary pumping processes. Its fabrication is presented, as well as modelling of the droplet dynamics associated with the MHE. The design uses a lead zirconate titanate (PZT) substrate as the base for the MHE, which has not been used previously in the literature to pattern microfluidic surfaces and devices. Although the surface roughness of the substrate may be larger than silicon 
substrates, it possesses excellent surface characteristics for the microfluidic motion. The effect of surface roughness on transport properties will be investigated in this study.

When heat is applied to one end of a droplet within a closed microchannel, an increase in temperature from the heat source at one side leads to a temperature gradient across the droplet. This results in the displacement of the droplet along the length of the channel towards the cooler end of the channel. This process is known as thermocapillary pumping (TCP). The resulting displacement increases the pressure at the closed end of the channel. The increased pressure is used to induce stress on a membrane at the closed end of the channel, which yields a mechanical deformation of the membrane. The mechanical deformation of the membrane results in the flow of electrons in an externally connected circuit, through a conversion of mechanical energy to electrical energy. A schematic of the MHE and the forces within the system are shown in Fig. 1.

Accurate prediction of the transient nature of the droplet motion and heat transfer in the MHE are needed by performing numerical and experimental studies. Past steady-state models have over-predicted the experimental observations [8]. Also, they indicated that surface roughness had a significant effect on the droplet velocity. Past numerical analyses of heat transfer and fluid flow in microchannels showed that thermocouples embedded in the channels influenced the flow regime [9]. Friction was also shown to affect the thermal performance of the microchannels [10, 11]. The frictional losses decreased upon heating of the channel at low Reynolds numbers, due to a change of viscosity of the fluid in the channel. Khan and Yovanovich [11] showed that lower fluid friction increases the heat transfer effectiveness in the channels. Past studies [12-14] showed that accurate predictions of the effects of surface roughness on the flow distribution are important for effective control of the droplet motion. The surface roughness has a significant effect on the wall velocity slip, pressure gradient and heat transfer coefficient in a microchannel. These flow processes are 
important to develop better theoretical models, which can more accurately predict the flow dynamics in microchannels.

Experimental results of the effects of surface roughness on heat transfer in circular channels $(1.06 \mathrm{~mm}, 0.62 \mathrm{~mm}$ diameters) were reported by Satish [15]. As the channel diameter decreases, the effect of surface roughness on heat transfer and pressure drop increases across the channel. A numerical model to investigate the effects of the different roughness patterns on the Poiseuille number and average Nusselt number was developed by Zhang et al. [16]. The roughness patterns included triangular, semicircular and rectangular patterns. Experimental results from this paper show that an average roughness height can be more accurate since patterns formed as a result of microfabrication are irregular. Experimental results for flow in a microtube were reported by Mala and Li [17]. At low Reynolds numbers, the Poiseuille flow assumption is sufficient for analytical predictions. However, the results showed that significant variations from the steady-state assumption are observed at higher Reynolds numbers. An empirical correlation was developed to predict the dynamic viscosity of the fluid for a rough surface.

A main difference between various methods of piezoelectric electricity generation in past studies is the nature of the applied force on the piezoelectric material, as necessary for deformation required to generate the electric voltage. Past studies have used combustion [5], electrostatic induction [18], mechanical vibrations [19] and acoustic vibrations [20] to achieve distortion of the crystallographic structure of the piezoelectric membrane to produce an electric displacement in a preferred direction. Glockner and Naterer [21] proposed a process of TCP for the deflection of a piezoelectric membrane. A $\mathrm{P}_{3}$ micro heat engine uses combustion in a closed channel [5] and makes use of the resulting membrane deflection to generate a voltage. Most of the past piezoelectric energy harvesting devices in past literature focus on a mechanical deformation using 
static loading conditions [22]. Cook-Chennault et al. [22] investigated the use of piezoelectric effects to harness energy from household devices with the aid of a bimorph composite of piezoelectric membranes.

Different configurations of inserts have also been investigated as energy harvesters using piezoelectric membranes [23, 24] in 31-mode loading conditions. These devices were able to produce high voltage, low current, and low energy devices capable of storing energy like a capacitor. A unique insert based on a two-layer unimorph curved membrane was developed by Yoon et al. [25]. The width of the membrane was found to have a more significant effect on the charge generation than its length. Also, increasing the thickness of the membrane improved the charge generation, but this can have an adverse effect on the load requirement to flex the membrane. Although an increased size of membrane will generally improve the quantity of charge, an optimal sizing of height, and length to width ratio, are required for a minimum force input.

In bio-medical applications, piezoelectrics have been used to generate energy from fluctuating blood pressure [26]. An energy harvester fabricated from PZT, which vibrates in a 33mode, has been developed to power orthopaedic knee implants [27]. The life-cycle was found to decrease linearly over 10 years of device usage. The power output between stacked and single layers of PZT of the micro-assembly were compared. The results indicated that stacking does not have any significant effect on power output, but a reduced voltage output was recorded. Low voltage output harvesters are relatively easier to integrate into devices where they are required.

This paper will present new experimental and analytical results of droplet motion, heat transfer and electricity generation associated with thermocapillary pumping in a micro heat engine. Typical forces, pressures, voltages and droplet velocities will be presented. The next section will 
present the experimental setup and procedures to investigate the operation of the MHE design. Detailed steps on the fabrication techniques will be outlined and an uncertainty analysis of the experimental measurements will be presented.

\section{Experimental method and apparatus}

The Centre of Integrated Radio Frequency Engineering (CIRFE) at the University of Waterloo, Ontario, was used to fabricate the MHE and perform experimental measurements. The complete assembly of the MHE is shown in Fig. 2. Fabrication steps of the MHE are highlighted in Figs. 3 - 5. The MHE was fabricated with PZT wafers manufactured by B and H Industries, California. Two sets of wafers of different thicknesses were examined for the fabrication $(100 \mu \mathrm{m}$ and $80 \mu \mathrm{m})$.

\subsection{Fabrication of micro heater}

Wafer cleaning was performed using an RCA 1 (Radio Corporation of America) cleaning procedure. The heaters were fabricated with Ti-W as the heating element. A combination of photolithography, sputtering, and wet etching were used to fabricate the heater. The sputtering was performed in the electron vacuum deposition chamber at $5 \times 10^{-6}$ Torr. A sacrificial layer was used to outline where Ti-W is deposited during the sputtering process. LOR 5A is first dispensed onto the substrate and spin coated at 500rpm for 5s and 3000rpm for 45s. The substrate was then soft baked for two minutes at $160^{\circ} \mathrm{C}$. AZ 3330 was deposited onto the cooled substrate and spin-coated at 500rpm for $15 \mathrm{~s}$ and $4000 \mathrm{rpm}$ for $45 \mathrm{~s}$ in one spin cycle. The substrate was soft baked at $90^{\circ} \mathrm{C}$ for five minutes on a vacuum hotplate and allowed to cool before exposure. The exposure was performed with a 365nm-UV wavelength mask aligner (Ultraviolet Illumination System (350 450nm) - Model 87000) for 14s. The post exposure baking (PEB) of substrate was then performed at $110^{\circ} \mathrm{C}$ for three minutes on the vacuum hotplate. The development used AZ's MIF 3000 
developer solution for 300s. The developed substrate was then hard baked on the hotplate for two minutes at $110^{\circ} \mathrm{C}$.

Ti-W was sputtered for about sixty minutes at a rate of 23Angstroms ( $\AA$ ) per minute to provide a film thickness of about 138nm. The liftoff used PG remover in an ultrasonic bath for between twenty and forty minutes. The ultrasonic bath was heated to a temperature of $38^{\circ} \mathrm{C}$ and the power setting as fixed at 3 Watts. The sample was placed in a fresh beaker of isopropyl alcohol (IPA) for three minutes to remove any traces of PG remover that may have remained on the sample. Figure 6 shows the completed Ti-W heaters.

\subsection{Back side etching}

The back of the substrate was etched to allow for flexing of the piezoelectric membrane. The etching pattern also created packaging support for the microassembly. The back of the substrate was processed using photolithography, sputtering and reactive ion etching (RIE). LOR 5A was spin coated on the substrate using a similar technique as outlined in section 2.1. AZ3330 was deposited as a sacrificial layer for the deposition of $\mathrm{Cr}$, $\mathrm{Au}$ and $\mathrm{Al}$. The process is the same as outlined in section 2.1. Then $300 \AA$ of $\mathrm{Cr}$ was deposited using the electron beam deposition, after which $500 \AA$ of Au was then deposited by a similar procedure. Al was sputtered at $180 \AA$ per minute for thirty minutes. The liftoff process was carried out under similar conditions as outlined in section 2.1. In order to protect the Ti-W heaters from the RIE process, AZ3330 was spin coated on the front side of the substrate to act as a masking layer. AZ3330 was then deposited with spinners at 500rpm for $15 \mathrm{~s}$ and $4000 \mathrm{rpm}$ for $45 \mathrm{~s}$ in one spin cycle. The substrate was then soft baked at $90^{\circ} \mathrm{C}$ for five minutes. 
Trion Phantom II plasma etcher was used to carry out RIE for this experiment. The sample was suspended in the chamber in order to produce the isotropic etching finish. The parameters used in the RIE process are listed as follows: inductive coupled plasma (ICP) power of 250W, radio frequency (RF) power of 200W, Argon (Ar) flow rate of 50Sccm, Sulphur hexafluoride $\left(\mathrm{SF}_{6}\right)$ flow rate of 5Sccm, etching pressure of 50mTorr, and etching time of 1,080s.

\subsection{Fabrication of microchannels}

Photolithography was used to process SU-8 2025. The photoresist was dispensed on the substrate and spin coated at 500rpm for 10s, 2000rpm for 15s, and 4000rpm for 20s in one spin cycle. Soft baking was performed at $65^{\circ} \mathrm{C}$ for two minutes and $95^{\circ} \mathrm{C}$ for five minutes. The exposure time for SU-8 using the UV mask aligner was 240s. Once the exposure was complete, the post exposure baking was performed for one minute at $65^{\circ} \mathrm{C}$ and five minutes at $95^{\circ} \mathrm{C}$. SU-8 Developer from Microchem was used to process the pattern after post-exposure baking. The optimal development time for SU-8 2025 was four minutes. The sample was then immersed in a solution of IPA for three minutes to remove any trace of the developer that may have remained on the substrate.

Bungard dry film laminator was used to seal the channel and secure the droplet within the channel. A thin film of about $17 \mu \mathrm{m}$ was used to laminate the top of the MHE. A Hamilton micro syringe was used to place the droplet on top of the channel. The hydrophobic property of deionised water (DI-water) on SU-8 kept the droplet in the required location before the lamination process. The laminator was used to force the water droplet into the channel and seal the channel. The laminator was set to a temperature of $95^{\circ} \mathrm{C}$ and a pressure of 2 bar with a roller speed of $0.5 \mathrm{~m} / \mathrm{s}$. 


\subsection{Experimental measurements and uncertainty}

The voltage and current supplied to the heater were measured by a four point probe method. A resistance of a known value was connected across the direct current (DC) power supply and the current was measured using a DC multimeter. This method was used to determine the current flowing through the resistor $(1 \mathrm{k} \Omega)$ when the voltage is regulated. The resistor and Ti-W heater were connected in series. A second DC voltmeter was connected across the Ti-W heater to measure the voltage generated. The power output from the heater can then be estimated from the measured voltage and sheet resistance across the Ti-W heater.

The uncertainty of the measurement was determined in accordance with the Kline and McClintock [28] method of estimating the uncertainty in a single sample experiment. This method was used to analyse the voltage and current measured across the heaters. The measurement of interest was the power output (q), which is a product of the voltage and current $(\mathrm{q}=\mathrm{VI})$. The uncertainty associated with measuring the power output was determined by the following correlation:

$U_{q}=\left[\left(\frac{\partial q}{\partial V} e_{v}\right)^{2}+\left(\frac{\partial q}{\partial I} e_{i}\right)^{2}\right]^{1 / 2}$

where $U_{q}$ is the uncertainty of the single sample measurement and $e_{v}, e_{i}$ are the uncertainties associated with measuring the voltage and current, respectively. The calculated uncertainty of the experiment varied between \pm 1 and $5 \%$ for the range of data considered in this study. The next section presents the analytical models used to predict the effect of heat supplied by the microheater on the transport phenomena, voltage production, and efficiency of the MHE. 


\section{Formulation of droplet dynamics and electricity generation}

Analytical models will be developed in this section to examine important physical phenomena that affect the operation of the MHE. Experimental results of Odukoya et al. [8, 29, 30] showed that earlier analytical models by Glockner and Naterer [21, 31] over-predicted the droplet displacement. This paper extends those past studies, to include surface tension hysteresis during initial start-up of droplet motion, modeling of the simultaneous effects of thermocapillary, pressure, and friction forces on the droplet displacement, and resulting friction irreversibilities.

\subsection{Surface roughness formulation}

Surface roughness affects the fluid momentum near the wall of a microchannel. This will affect the velocity profile of the flow motion. Mala and Li [17] developed a modified roughness viscosity model, which accounts for the momentum change along the wall of microchannels. The modified fluid viscosity is the sum of the roughness viscosity and fluid viscosity. The apparent viscosity can be represented as

$\mu_{\text {app }}=\mu_{R}+\mu_{f}$

The apparent viscosity can be used to model the flow of water in a microchannel. Qu et al.

[14] developed an analytical model to determine the ratio of the roughness viscosity to the fluid viscosity, expressed as:

$$
\frac{\mu_{R}}{\mu}=A_{p} \operatorname{Re}_{K} \times \frac{\left(R_{h}-l_{\text {min }}\right)}{K}\left[1-\exp \left(-\frac{\operatorname{Re}_{K}}{\operatorname{Re}} \frac{\left(R_{h}-l_{\text {min }}\right)}{K}\right)\right]^{2}
$$

where $A_{p}$ is the coefficient of roughness viscosity, determined by an empirical correlation of the experimental data, $R e_{K}$ is the local roughness Reynolds number, and $l_{\min }$ is the shortest distance between the peaks of the roughness elements and the channel wall, 


$$
A_{p}=5.8\left(\frac{R_{h}}{K}\right)^{0.35} \times \exp \left[\operatorname{Re}^{0.94}\left(5.0 \times 10^{-5} \frac{R_{h}}{K}-0.0031\right)\right]
$$

where $K$ is the height of the roughness element and $R_{h}$ is the hydraulic radius. The height of the roughness element must be determined experimentally. The apparent viscosity is determined by examining the substrate under a scanning electron microscope to determine the profile of the surface roughness. A profilometer is used to estimate the roughness height. The estimated viscosity is the substituted into the equation of motion of the droplet to obtain a better correlation between the theoretical and experimental results. In this paper, a Dektak profilometer was used to measure the roughness height of the substrate.

\subsection{Transient velocity formulation}

Unsteady viscous flow occurs when a sudden pressure gradient is applied to the droplet motion within the microchannel. Several channel geometries have been investigated in past literature [32-35], ranging from circular, rectangular, and non-circular geometries. The sudden pressure gradient can be induced by a uniformly distributed heat source via conduction through the substrate. If the heat source is continuous over time, the flow will approach a steady state and the transient effect can be negligible. The short period observed in the experiments of the MHE suggested that the droplet motion never actually reached a steady state, necessitating this present investigation into its short time flow behaviour. Szymanski [32] developed a solution of transient flow in circular tube. A solution of flow within a parallel channel was developed by Rouse and Arpaci et al. [33, 34]. Solutions to circular and rectangular configurations were presented by Muller et al. and Erdogan et al. [36, 37].

Many or most of these past solutions used numerical methods. An analytical model for arbitrary configurations was developed by Muzychka and Yovanovich [37]. This paper extends 
this latter model to predict the transient velocity in a closed microchannel. There is no known model (to our knowledge) that predicts the transient start-up flow of droplets in closed microchannels. The velocity and displacement of a droplet can be determined by integration of the equation of motion of the droplet, thereby yielding

$$
\begin{aligned}
& u=u^{o}+F \frac{\Delta t}{m} \\
& x=x^{o}+u \Delta t
\end{aligned}
$$

where $m$ is the mass of the droplet, and $u^{o}$ and $x^{o}$ are the velocity and displacement at the previous time step. The force exerted on a droplet in a closed rectangular microchannel, based on a slug flow approximation (droplet modeled as a single lumped mass) can be dervied as:

$$
F=G A\left[\left(\frac{\sigma \cos \theta}{H}\right)_{R}-\left(\frac{\sigma \cos \theta}{H}\right)_{L}\right]+A R\left[\left(\frac{m_{a} T_{a}}{V_{a}}\right)_{L}-\left(\frac{m_{a} T_{a}}{V_{a}}\right)_{R}\right]+\frac{12}{H} \mu A u_{b} \Delta x
$$

where $\mathrm{G}=2$ for a rectangular microchannel, $\theta$ is the contact angle and $\mu$ is fluid viscosity. The terms on the right hand side of the equation represent the thermocapillary, external air and frictional forces, respectively. The transient velocity can be estimated from the spatial integral of the instantaneous velocity of the droplet,

$$
\bar{u}=\frac{1}{A} \iint_{A} u d A
$$

where $\bar{u}$ is the average velocity and $A$ is the cross sectional area. Using the Poisson equation of fluid motion, the instantaneous velocity distribution can be determined by

$$
\frac{1}{v} \frac{d u}{d t}=\frac{1}{\mu} \frac{\Delta P}{L}+\nabla^{2} u
$$


Based on the Muzychka and Yovanovich analogy $[37,38]$ of a short time flow scale in the case of the MHE, the dimensionless velocity as $\mathrm{t} \rightarrow 0$ can be written as

$$
u^{*}=\frac{\bar{u}}{\psi \frac{1}{\mu} \frac{\Delta P}{L}}=\frac{v t}{\psi^{2}}
$$

where $\psi$ is an arbitrary length scale. Within the boundary layer, a mass balance leads to:

$$
\frac{1}{v} \frac{d \bar{u}}{d t}=\frac{\bar{u}}{\delta^{* 2}} \rightarrow \delta^{*}=\sqrt{v t}
$$

Poisson's equation in equation (9) will be solved in the region of the boundary layer based on the boundary conditions of $u^{*}(0)=0$ and $u^{*}(t)=t^{*}$ for a short time. Using the Stokes equation for momentum transport, the boundary layer thickness can be estimated as

$$
\delta^{*}=\frac{2}{\pi} \sqrt{v t} \approx 1.128 \sqrt{v t}
$$

The length is determined from the hydraulic radius for a rectangular microchannel and it is taken as $\psi=4 A / p$, where $A$ is the cross-sectional area and $p$ is the wetted perimeter. Muzychka and Yovanovich [37] recommended $\psi=\sqrt{A}$ for arbitrary cross sections. Using the start-up velocity and modifying the equation of motion in equation (5), an expression is obtained for the velocity in a closed microchannel. The acceleration of the droplet is the determined based on the net change in air pressure in the closed channel. The transient velocity distribution is determined by a temporal integration of the equation of motion. The transient velocity in a closed channel can be written as

$$
u(t)=\left[\psi^{2} \frac{1}{\mu} \frac{\Delta P}{L}\right]\left[t^{n}+\left(\frac{P_{\varsigma} \sqrt{A}}{p}\right)^{n}\right]^{1 / n}+\left[R\left[\left(\frac{m_{a} T_{a}(t)}{V_{a}}\right)_{R}-\left(\frac{m_{a} T_{a}(t)}{V_{a}}\right)_{L}\right]\right] \frac{t}{m_{d}}
$$


where $P_{\varsigma}$ is the Poiseuille number of the flow. The asymptotic value of $n$ is determined based on the aspect ratio of the channel. Extending the asymptotic correlation of Churchill and Usagi [39] to a closed channel where $u_{\infty}$ tends to zero:

$u^{*}=\left[\left(u_{o}^{*}\right)^{n}+\left(u_{\infty}^{*}\right)^{n}\right]^{1 / n}$

Once the transient velocity is known, its effect on voltage generation will be determined from the following analytical model of the voltage production within the MHE. The next section presents this analytical modeling of the voltage generation of the MHE, as well as its efficiency.

\subsection{Electricity generation model}

The sum of the strain energy due to deformation and internal stresses yields the total strain energy on the piezoelectric membrane. The strain energy due to bending can be neglected for very thin films if the deflection is much larger than the thickness of the membrane [40]. Tabata et al. [41] used the energy minimization approach to determine the load-deflection in thin rectangular membranes. The relationship between pressure on the membrane and thickness of the membrane can be determined by the following relationship:

$$
P=\frac{t_{p z t}}{b^{2}} w_{m}\left[C_{1} \gamma_{o}+\frac{f(v)}{b^{2}} \frac{E}{1-v} w_{m}^{2}\right]
$$

where $t$ is the thickness of the membrane, $b$ is the width of the membrane, $\gamma_{0}$ is the residual stress in the membrane, $v$ is Poisson's ratio, $E$ is Young's modulus of the membrane, and $C_{1}$ and $f(v)$ are geometry dependent constants.

The effect of the droplet motion on the piezoelectric membrane will be modeled as a uniformly distributed pressure that is applied to a thin membrane. This requires analysis of the 
bending moment of each layer about a neutral axis relative to the piezoelectric membrane. The equation for determining the pressure due to stresses in the longitudinal and transverse directions across the membrane is given as follows:

$$
P=\frac{12}{E t_{p z t}^{2}(1-v)}\left(\frac{\partial^{4} w_{m}}{\partial x^{4}}+2 \frac{\partial^{4} w_{m}}{\partial x^{2} \partial y^{2}}+\frac{\partial^{4} w_{m}}{\partial y^{4}}\right)
$$

Re-arranging equation (16), the deflection of the membrane can be expressed in terms of pressure exerted on the membrane. The pressure gradient across the channel is determined from the force balance across the droplet within the mocrochannel.

The voltage produced by the piezoelectric membrane is a measure of the potential difference across the membrane. The deflection of the membrane is based on the change in pressure in the microchannel. The deflection can be related to the stress and strain in the piezoelectric membrane as follows,

$$
D_{i}=d_{i j} T_{j}+\Phi V_{e}
$$

where $D_{i}, d_{i j}, T_{j}, \Phi, V_{e}$ are the electrical polarization, piezoelectric coefficient matrix, applied mechanical stress, electric permittivity matrix, and the induced electric field. Since no electric field is induced to generate the voltage, equation (17) can be reduced to a matrix as follows:

$$
\left[\begin{array}{l}
D_{1} \\
D_{2} \\
D_{3}
\end{array}\right]=\left[\begin{array}{llllll}
d_{11} & d_{12} & d_{13} & d_{14} & d_{15} & d_{16} \\
d_{21} & d_{22} & d_{23} & d_{24} & d_{25} & d_{26} \\
d_{31} & d_{32} & d_{33} & d_{34} & d_{35} & d_{36}
\end{array}\right]\left[\begin{array}{l}
T_{1} \\
T_{2} \\
T_{3} \\
T_{4} \\
T_{5} \\
T_{6}
\end{array}\right]=d_{i j} T_{j}=\left[\begin{array}{ccllll}
0 & 0 & 0 & 0 & 584 & 0 \\
0 & 0 & 0 & 584 & 0 & 0 \\
-171 & -171 & 374 & 0 & 0 & 0
\end{array}\right]\left[\begin{array}{c}
T_{1} \\
T_{2} \\
T_{3} \\
T_{4} \\
T_{5} \\
T_{6}
\end{array}\right]
$$


The piezoelectric matrix coefficient depends on the nature of the piezoelectric material in the fabrication. The choice of piezoelectric material for this fabrication will be PZT-5. The $T_{1}, T_{2}$, and $T_{3}$ variables are the normal stresses, while $T_{4}, T_{5}$, and $T_{6}$ are the shear stresses in the channel. The mechanical stress occurs when heat is applied to the droplet and it is directly related to the change in pressure across the channel. The effect of the shear stress on the membrane is expected to be relatively small for the current design. The efficiency of the MHE can be estimated relative to the voltage produced from the piezoelectric membrane.

The maximum deflection of the piezoelectric membrane will occur at the center of the membrane. This displacement can be expressed as:

$$
w_{m_{\text {center }}}=\frac{\beta P b^{4}}{E_{\text {comp }} t_{p z t}{ }^{3}}
$$

where $\beta$ is a constant related to a ratio of the length to width of the membrane and $P$ is the uniform pressure on the membrane. The width of the membrane is represented by $b, E$ is Young's modulus of elasticity, and $t_{p z t}$ is the thickness of the membrane. The relationship in equation (19) can be extended to the mechanical stress on the membrane in the direction of the membrane as follows [42],

$T_{j}=\frac{\chi P_{i j} b^{2}}{t_{p z t}^{2}}$

where $\chi$ is a constant based on the ratio of the length to the width of the membrane. The estimated values of $\chi(0.1386)$ and $\beta(0.0138)$ [42] are constant for any ratio of the length to width of the membrane, but they differ at the maximum normal stress. Substitution of equation (20) into equation (18) will be used to estimate the generated voltage from the membrane. 
The net in-plane stress can be used to determine the location of the neutral axis, which is the point at which the stress makes the bending effect negligible. The position $Z_{n}$ is determined by taking account of each layer from the bottom to the top of the membrane, yielding:

$$
Z_{n}=\frac{\sum_{i}\left(Z_{i} E_{i} A_{i}\right)}{\sum_{i} E_{i} A_{i}}
$$

where $Z_{i}$ is the height of each material from the base of the structure, $A_{i}$ is the cross-sectional area of each material and $E_{i}$ is the Young's modulus of elasticity for each material. The Young's modulus of elasticity of the composite structure is determined based on the ratio of the moment of inertia to the total moment of inertia.

$$
E_{\text {comp }}=\sum_{i} E_{i}\left(\frac{I_{i}}{I_{\text {total }}}\right)
$$

The piezoelectric membrane deflection can be approximated as the bending of a simply supported beam under load. Murralt [43] and Cho et al. [40] showed that the electromechanical coupling factor could be approximated as:

$$
k_{p}^{2}=\frac{8}{\pi^{2}} \frac{G_{f}^{2}}{K_{b}} t_{p z t} \frac{\left(d_{31} / s_{11}^{E}\right)^{2}}{\varepsilon_{33}^{T}\left(1-\frac{d_{31}^{2}}{s_{11}^{E} \varepsilon_{33}^{T}}\right)}=\frac{\text { Energy converted }}{\text { Energy input }}
$$

where $G_{f}$ is the leverage factor, and $K_{b}$ is the bending modulus. The leverage factor can be determined relative to the neutral axis as follows:

$$
G_{f}=\left(t_{s u b}-Z_{n}+\frac{t_{p z t}}{2}\right)
$$


The bending modulus is determined from an integration of the moment per unit length about the neutral axis using appropriate boundary conditions [40].

$$
K_{b}=E_{\text {sub }} t_{\text {sub }}\left(\frac{t_{\text {sub }}^{2}}{3}-t_{\text {sub }} Z_{n}+Z_{n}^{2}\right)+\alpha t_{p z t}\left(t_{\text {sub }}^{2}-2 Z_{n} t_{\text {sub }}+t_{\text {sub }} t_{p z t}+Z_{n}^{2}-Z_{n} t_{p z t}+\frac{t_{p z t}^{2}}{3}\right)
$$

where

$$
\alpha=\frac{1}{s_{11}^{E}\left(1-\frac{d_{31}^{2}}{s_{11}^{E} \varepsilon_{33}^{T}}\right)}
$$

The predicted efficiency of the MHE can then be determined from the relationship between the electromechanical coupling factor and the quality factor of the piezoelectric membrane. The energy input in the experimental setup will be equivalent to the heat supplied to the electric heaters to generate the droplet motion. This can be estimated based on the resistance of the heaters and current supplied to the heaters. The efficiency of the system, based on experimental measurements, is then estimated by the ratio of the power supplied to the heaters to the energy generated by the piezoelectric membrane under a resistive load.

The efficiency determined from the experimental measurements could also be compared with analytical approximations of the efficiency based on the coupling coefficient. The power density of the energy harvester will determine its viability.

$$
\eta=\frac{\frac{1}{2}\left(\frac{k_{p}^{2}}{1-k_{p}^{2}}\right)}{\frac{1}{Q_{f}}+\frac{1}{2}\left(\frac{k_{p}^{2}}{1-k_{p}^{2}}\right)}=\frac{\text { Energy converted }}{\text { Energy input }}=\frac{I_{\text {in }}^{2} r_{\text {heater }}}{V_{D_{\text {out }}}^{2} / r_{p z t}}
$$


The following section highlights results from the analytical predictions and experimental results. Experimental results are also compared with the predicted models to validate the analytical modeling.

\section{Results and discussion}

The effects of temperature gradient, transient heat flux and surface roughness on the droplet motion will be presented in this section. These results will be presented along with other analytical models that predict the voltage generation and efficiency of the MHE. Experimental results for power output from the microheater will be presented and compared with predicted results from analytical modeling of the heating processes.

The main effect of surface roughness on flow in the microchannel is altering the "effective viscosity" of the droplet. Any changes in viscous force will affect the pressure gradient across the channel as modelled in equation (7). The effective viscosity is inversely proportional to the Reynolds number of the flow of the droplet in the microchannel. Although the percentage variation is only about $\pm 1.5 \%$ for the range of Reynolds numbera in this study, the impact at this scale can have a significant effect on the frictional force. The effective viscosity increases as the Reynolds number increases for open channel flow [17], but the reverse occurs for a closed channel. This is due to the restraint of the fluid motion as the droplet moves towards the right end of the channel. The effect of the viscosity decreases towards the centre of the droplet, due to the diminishing effects of the boundary layer in the radial direction. The frictional force variation for different local roughness Reynolds numbers $\left(R e_{e k}\right)$ is indicated in Fig. 7. The choice of $R e_{e k}$ is based on measurement of the roughness height, which varies from $2-3 \mu \mathrm{m}$ as measured for different samples of the PZT substrate. The frictional force increases with an increase in the roughness height as observed in Fig. 7, which is as a result of the increase in local roughness mean velocity. 
The frictional force is approximately doubled for an increase of $R e_{e k}$ from 0.1 to 0.3 . This further indicates the importance of the effect of surface roughness on the droplet displacement in the microchannel. The frictional force is inversely proportional to the bulk Reynolds number of the flow. The average bulk velocity increases with Reynolds number, thereby reducing the impact of the frictional force on the bulk motion of the droplet. The frictional force is smaller than other forces acting in the microchannel, as observed in Fig. 8. The capillary force is the main force that drives the motion of the droplet. As expected, it increases rapidly when heat is added to the droplet. The air force and frictional force act in opposite directions of the capillary force as the droplet moves from the left to the right end of the channel. The combined effect of air and frictional forces reduces the bulk velocity of the droplet to zero.

Results will be presented for simulations of the droplet displacement in a closed $60 \times 60 \times$ $15,000 \mu \mathrm{m}$ rectangular microchannel. The properties used for performing the simulation are shown in Table 1. Figure 9 shows the effects of droplet displacement on the pressure exerted on the piezoelectric membrane and temperature of the droplet. The change in pressure is rapid with initial displacement of the droplet, but the rate of change decreases due to the external air pressure from the closed end of the channel. The total pressure change is about $0.1 \mathrm{kPa}$, for a maximum deflection of about $13 \mu \mathrm{m}$, which is obtained from the piezoelectric with the largest thickness.

The change in deflection occurs in steps. It remains constant for a certain range of displacement for the different thicknesses. The overall change in deflection increases with a larger displacement of the droplet. However, when the different thicknesses are considered for a specific displacement, the change is approximately doubled between a thickness of 500 and $700 \mathrm{~nm}$, but only about $77 \%$ between 300 and 500nm. The voltage produced as a result of the deflection of the membrane was compared for three thicknesses in Fig. 10. The voltage produced in the MHE is 
proportional to the thickness of the membrane, whereby the largest thickness produced the highest voltage, which varied between 1.2 and $1.3 \mu \mathrm{V}$.

The change in voltage for the range of displacements is about $1.7 \%$. A steady supply can be achieved within a reasonable confidence interval. The lowest voltage was observed for the $300 \mathrm{~nm}$ membrane, with a value of $0.5 \mathrm{mV}$. This suggests that the thickness of the membrane can be used to control the application in which the MHE is utilized. The voltage production is affected by the bulk velocity of the droplet. The transient velocity was investigated in order to predict the impact on the voltage production in the MHE. The predictive model was validated against past data of Muzychka [37].

The dimensionless velocity was compared for different characteristic length scales, which affect the Reynolds number of the flow (Fig. 11). For different aspect ratios, the trends showed good agreement with Muzychka's model. The transient velocity was compared with Poiseuille flow in Fig. 12. It can be observed that the Poiseuille flow assumption overpredicted the bulk velocity of the droplet. At early times, the difference in velocities is minimal but a significant deviation is observed at about $30 \mu$ s. The droplet quickly attains a maximum velocity in the transient model and also decreases much faster than the case with the Poiseuille flow assumption.

The maximum variation in the velocity when the droplet is advancing is about $33 \%$. The droplet stops in about half of the time observed with the Poiseuille flow assumption, which indicates a faster response time will be achieved in the MHE. Over-predicting the velocity of the droplet affects the predicted voltage from the MHE. Fig. 13 shows a comparison of the effect of the transient and Poiseuille flow assumption on the voltage production in the MHE. The output voltage is over-predicted by the steady flow assumption by almost double its transient result. The corrected voltage can be used to estimate the efficiency of the MHE. The effect of the displacement 
of the droplet on the efficiency of the MHE is shown in Fig. 14. It can be observed that the trends are similar to the results in Fig. 10. The results suggest that voltage production is directly proportional to the system efficiency. The maximum efficiency is about $1.67 \%$ for the $700 \mathrm{~nm}$ membrane for the largest droplet displacement. The minimum efficiency is about $0.7 \%$ for the $300 \mathrm{~nm}$ membrane. The total change in efficiency is about $0.02 \%$ for the range of droplet displacements. In practice, a compromise must be made between efficiency and cost of the material and fabrication.

A four point probe test was used to determine the sheet metal resistance of Ti-W. The resistivity of Ti-W sputtering deposition varies with residual stress as a result of the deposition process and the pressure at which it is deposited $\left(5.6 \times 10^{-6}\right.$ Torr $)$. The resistance can be estimated based on the sheet metal resistance, $r=\rho\left(\frac{L}{w}\right)$

where $\rho$ is the sheet metal resistance obtained from the four probe measurement, and $w$ and $L$ are the width and the length of the heater, respectively. Based on the estimated resistance in equation (28), the actual heat flux transferred to the heater can be estimated from the measured contact area of the heaters and channels. The resistivity cited in past literature [44] was used to estimate the heat flux into the system. The measured resistivity of Ti-W from the experiment varied between 21 and $31 \Omega / \mathrm{m}^{2}$ for a deposition of $138 \mathrm{~nm}$. The resistance is inversely proportional to the thickness of the deposition. A non-dimensional comparison was made based on the measured voltage, current and heat flux in Fig. 15. This is analogous to the non-dimensional heat flux supplied to one microchannel. 
The heat flux curve in Fig. 15 shows the relationship between voltage and power supplied to the heaters. The experimental and predicted results exhibit good agreement. The deviation from the predicted results may be associated with irreversibilities in the connections and heat losses to the substrate and surroundings. The resistance of the Ti-W heater was estimated to vary between $893-918 \mathrm{k} \Omega$ for the range of measured voltages across the heater. This was used to estimate the actual sheet resistance of Ti-W. The predicted and experimental measurements show good agreement for the range of voltages in the four point probe test. The maximum variation in the resistance is only about $\pm 2.7 \%$, which indicates a uniformly distributed heat flux could be achieved for a wide range of heat inputs. The measured heat flux supplied to each microchannel was between 1.2 and $120 \mu \mathrm{W} / \mathrm{m}^{2}$.

\section{Conclusions}

This paper examined the use of a PZT substrate for surface micromachining in microchannel flows. Past studies have used silicon or glass substrates for surface micromachining of microfluidic devices. This study has shown the feasibility of fabricating microheaters using TiW. It also presented experimental and analytical results to verify the use of a microheater to generate a heat flux beneath the microchannel. The surface roughness was shown to have less impact on the droplet flow as the average bulk velocity of the fluid increased. New analytical results have been presented to determine the transient behaviour of the velocity of the droplet in a closed microchannel. A comparison was made between the steady state and transient approximations of the bulk velocity of the droplet with a time lag between both peaks. The peak transient velocity is about half of the peak of the steady state velocity. It was also shown that a similar effect is translated into a lower voltage when the transient droplet motion is considered. The efficiency of the MHE was presented for different thicknesses of the piezoelectric membrane. 
The analytical study showed that the efficiency varied between 0.7 and $1.6 \%$ for the range of thicknesses. Although this efficiency appears relatively low, the exergy efficiency is relatively high, as the Carnot cycle efficiency for this system for an ambient temperature of $25^{\circ} \mathrm{C}$ is about $4.4 \%$ for the maximum temperature of the MHE.

\section{$\underline{\text { Acknowledgements }}$}

Financial support from the Canada Research Chairs program and the Natural Sciences and Engineering Research Council of Canada (NSERC) is gratefully acknowledged. The support of the members of the Centre of Integrated Radio Frequency Engineering group (CIRFE), University of Waterloo, Waterloo, ON, is also acknowledged.

\section{References}

[1] Wu, S., Mai, J., Tai, Y. C., 1999, "Micro heat exchanger by using MEMS impinging jets," Proceedings of 12th International Workshop on Micro Electro Mechanical Systems - MEMS, IEEE, Piscataway, NJ, USA, pp. 171-176.

[2] Vafai, K., and Zhu, L., 1999, "Analysis of Two-Layered Micro-Channel Heat Sink Concept in Electronic Cooling," International Journal of Heat and Mass Transfer, 42(12) pp. 2287-2297.

[3] Tudos, A. J., Besseling, G. A. J., and Schasfoort, R. B. M., 2001, "Trends in Miniaturized Total Analysis Systems for Point-of-Care Testing in Clinical Chemistry," Lab on a Chip, 1(2) pp. 8395.

[4] Naterer, G. F., Glockner, P. S., Thiele, D., 2005, "Surface Micro-Grooves for Near-Wall Exergy and Flow Control: Application to Aircraft Intake De-Icing," Journal of Micromechanics and Microengineering, 15(3) pp. 501-13. 
[5] Whalen, S., Thompson, A., Bahr, D., 2003, "Design, Fabrication and Testing of the P3 Micro Heat Engine," Sensors and Actuators A (Physical), A104(3) pp. 290-298.

[6] Yang, J., Lu, F., Kostiuk, L. W., 2003, "Electrokinetic Microchannel Battery by Means of Electrokinetic and Microfluidic Phenomena," Journal of Micromechanics and Microengineering, 13(6) pp. 963-970.

[7] Regan, B. C., Aloni, S., Jensen, K., 2005, "Surface-Tension-Driven Nanoelectromechanical Relaxation Oscillator," Applied Physics Letters, 86(12) pp. 123119-123120.

[8] Odukoya, A., Naterer, G. F., and Dincer, I., 2011, "Entropy Generation of Droplet Motion with Surface Tension Hysteresis in a Closed Microchannel," Journal of Micromechanics and Microengineering, 21(9) (in press).

[9] Luciani, S., and Le Niliot, C., 2008, "Local heat transfer estimation in microchannels during convective boiling under microgravity conditions: 3D inverse heat conduction problem using BEM techniques," 6th International Conference on Inverse Problems in Engineering: Theory and Practice, IOP Publishing Ltd, UK, 135, pp. 12067 -12075.

[10] Toh, K. C., Chen, X. Y., and Chai, J. C., 2002, "Numerical Computation of Fluid Flow and Heat Transfer in Microchannels," International Journal of Heat and Mass Transfer, 45(26) pp. 5133-5141.

[11] Khan, W. A., and Yovanovich, M. M., 2007, "Analytical modeling of fluid flow and heat transfer in micro/nano-channel heat sinks," IPACK2007, ASME, New York, NY, USA, 1, pp. 109120. 
[12] Rosengarten, G., Cooper-White, J., and Metcalfe, G., 2006, "Experimental and Analytical Study of the Effect of Contact Angle on Liquid Convective Heat Transfer in Microchannels," International Journal of Heat and Mass Transfer, 49(21-22) pp. 4161-70.

[13] Croce, G., D'agaro, P., and Nonino, C., 2007, "Three-Dimensional Roughness Effect on Microchannel Heat Transfer and Pressure Drop," International Journal of Heat and Mass Transfer, 50(25-26) pp. 5249-59.

[14] Qu, W., Mala, M., and Li, D., 2000, "Heat Transfer for Water Flow in Trapezoidal Silicon Microchannels," International Journal of Heat and Mass Transfer, 43(21) pp. 3925-36.

[15] Kandlikar, S. G., Joshi, S., and Tian, S., 2001, "Effect of channel roughness on heat transfer and fluid flow characteristics at low reynolds numbers in small diameter tubes," 2001 National Heat Transfer Conference (NHTC2001), June 10, 2001 - June 12, American Society of Mechanical Engineers, Ananheim, CA, United states, 2, pp. 1609-1618.

[16] Zhang, C., Chen, Y., and Shi, M., 2010, "Effects of Roughness Elements on Laminar Flow and Heat Transfer in Microchannels," Chemical Engineering and Processing, 49(11) pp. 11881192.

[17] Mala, M., and Li, D., 1999, "Flow Characteristics of Water in Microtubes," International Journal of Heat and Fluid Flow, 20(2) pp. 142-148.

[18] Miyazaki, M., Tanaka, H., Ono, G., 2004, "Electric-Energy Generation through VariableCapacitive Resonator for Power-Free LSI," IEICE Transactions on Electronics, E87-C(4) pp. 549555. 
[19] Kasyap A., Lim J., Johnson D., Horowitz S., Nishida T., Ngo K., Sheplak M., Cattafesta L., 2002, "Energy Reclamation from a Vibrating Piezoelectric Composite Beam," 9th Annual Conference on Sound and Vibration Orlando, Fl, pp. pp. 36-43.

[20] Horowitz, S., Kasyap, A., Liu, F., 2002, "Technology development for self-powered sensors," Proc. of 1st Flow Control Conference, St. Louis, Mo. pp. 2002-2702.

[21] Glockner, P. S., and Naterer, G. F., 2005, "Thermocapillary Control of Microfluidic Transport with a Stationary Cyclic Heat Source," Journal of Micromechanics and Microengineering, 15(12) pp. 2216-2229.

[22] Cook-Chennault, K. A., Thambi, N., Bitetto, M. A., 2008, "Piezoelectric Energy Harvesting: A Green and Clean Alternative for Sustained Power Production." Bulletin of Science, Technology and Society, 28(6) pp. 14.

[23] Shenck, N. S., and Paradiso, J. A., 2001, "Energy Scavenging with Shoe-Mounted Piezoelectrics," IEEE Micro, 21(3) pp. 30-42.

[24] Mateu, L., and Moll, F., 2005, "Optimum Piezoelectric Bending Beam Structures for Energy Harvesting using Shoe Inserts," Journal of Intelligent Material Systems and Structures, 16(10) pp. 835-845.

[25] Yoon, H. S., Washington, G., and Danak, A., 2005, "Modeling, Optimization, and Design of Efficient Initially Curved Piezoceramic Unimorphs for Energy Harvesting Applications," Journal of Intelligent Material Systems and Structures, 16(10) pp. 877-888. 
[26] Ramsay, M. J., and Clark, W. W., 2001, "Piezoelectric energy harvesting for bio MEMS applications," Smart Structures and Materials 2001: Industrial and Commercial Applications of Smart Structures Technologies, SPIE-Int. Soc. Opt. Eng, USA, 4332, pp. 429-438.

[27] Platt, S. R., Farritor, S., and Haider, H., 2005, "On Low-Frequency Electric Power Generation with PZT Ceramics," IEEE/ASME Transactions on Mechatronics, 10(2) pp. 240-252.

[28] Kline, S. J., and McClintock, F., 1953, "Describing Uncertainties in Single-Sample Experiments," Mechanical Engineering, 75(1) pp. 3-8.

[29] Odukoya, A., and Naterer, G. F., 2010, "Experimental study of droplet motion and thermocapillary heat transfer in a closed microchannel," 10th AIAA/ASME Joint Thermophysics and Heat Transfer Conference, June 28, 2010 - July 1, American Institute of Aeronautics and Astronautics Inc, Chicago, IL, United states, .

[30] Yang, Y., Odukoya, A., and Naterer, G. F., 2010, "Droplet meniscus motion of thermocapillary pumping in a closed microchannel with external heating," 2010 12th IEEE Intersociety Conference on Thermal and Thermomechanical Phenomena in Electronic Systems, ITherm 2010, June 2, 2010 - June 5, IEEE Computer Society, Las Vegas, NV, United states, .

[31] Glockner, P. S., and Naterer, G. F., 2006, "Surface Tension and Frictional Resistance of Thermocapillary Pumping in a Closed Microchannel," International Journal of Heat and Mass Transfer, 49(23-24) pp. 4424-4436. 
[32] Szymanski, P., 1932, "Some Exact Solutions of the Hydrodynamic Equations of a Viscous Fluid in the Case of a Cylindrical Tube," Journal de Mathématiques Pures et Appliquées, 11pp. 67-107.

[33] Appel, D. W., Hubbard, P., Landweber, L., 1959, "Advanced Mechanics of Fluids," Physics Today, 12pp. 54.

[34] Arpaci, V. S., and Larsen, P. S., 1984, "Heat Engineering Convection Heat Transfer," Prentice-Hall, Englewood Cliffs NJ, United States.

[35] Erdogan, M. E., 2003, "On the Flows Produced by Sudden Application of a Constant Pressure Gradient Or by Impulsive Motion of a Boundary," International Journal of Non-Linear Mechanics, 38(5) pp. 781-797.

[36] Erdogan, M. E., and Imrak, C. E., 2007, "On some Unsteady Flows of a Non-Newtonian Fluid," Applied Mathematical Modelling, 31(2) pp. 170-180.

[37] Muzychka, Y. S., and Yovanovich, M. M., 2004, "Compact models for transient conduction or viscous transport in non-circular geometries with a uniform source," 2004 ASME International Mechanical Engineering Congress and Exposition, IMECE, November 13, 2004 - November 19, American Society of Mechanical Engineers, Anaheim, CA, United states, 375, pp. 161-172.

[38] Muzychka, Y. S., and Yovanovich, M. M., 2006, "Unsteady viscous flows and Stokes's first problem," 2006 ASME International Mechanical Engineering Congress and Exposition, IMECE2006, November 5, 2006 - November 10, American Society of Mechanical Engineers, Chicago, IL, United states, . 
[39] Churchill, S., and Usagi, R., 1972, "A General Expression for the Correlation of Rates of Transfer and Other Phenomena," AICHE Journal, 18(6) pp. 1121-1128.

[40] Cho, J., Anderson, M., Richards, R., 2005, "Optimization of Electromechanical Coupling for a Thin-Film PZT Membrane: II. Experiment," Journal of Micromechanics and Microengineering, 15(10) pp. 1804-1809.

[41] Tabata, O., Kawahata, K., Sugiyama, S., 1989, "Mechanical Property Measurement of Thin Films using Load-Deflection of Composite Rectangular Membranes," Sensors and Actuators, 20(1-2) pp. 135-141.

[42] Liu, C., 2006, "Foundation of MEMS," Pearson Prentice Hall, Upper Saddle River, NJ, United |States.

[43] Muralt, P., 1997, "Piezoelectric thin films for MEMS," Ninth International Symposium on Integrated Ferroelectrics, Gordon \& Breach, Netherlands, 17, pp. 297-307.

[44] Glebovsky, V., Yaschak, V. Y., Baranov, V., 1995, "Properties of Titanium-Tungsten Thin Films obtained by Magnetron Sputtering of Composite Cast Targets," Thin Solid Films, 257(1) pp. 1-6. 


\begin{tabular}{|l|l|}
\hline Property & Value \\
\hline Conductivity of droplet & $0.606 \mathrm{~W} / \mathrm{mK}$ \\
\hline Height of droplet & $60 \mu \mathrm{m}$ \\
\hline Height of air & $60 \mu \mathrm{m}$ \\
\hline Height of substrate & $500 \mu \mathrm{m}$ \\
\hline Thermal diffusivity & $4.588 \mathrm{~m}^{2} \mathrm{~s}^{-1}$ \\
\hline Thermal conductivity of air & $0.0263 \mathrm{~W} / \mathrm{mK}$ \\
\hline Conductivity of substrate & $0.96 \mathrm{~W} / \mathrm{mK}^{-1}$ \\
\hline Heat transfer coefficient & $4.82 \mathrm{Wm}{ }^{2} / \mathrm{K}$ \\
\hline Heat flux & $3.423 \mathrm{~W} / \mathrm{m}^{2}$ \\
\hline Density of droplet & $998 \mathrm{~kg} / \mathrm{m}^{3}$ \\
\hline Density of substrate & $2,500 \mathrm{~kg} / \mathrm{m}^{3}$ \\
\hline Density of air & $1.16 \mathrm{~kg} / \mathrm{m}^{3}$ \\
\hline Length of channel & $15 \mathrm{~mm}$ \\
\hline
\end{tabular}

Table 1: Parameters and thermophysical properties for rectangular channel with PZT substrate 


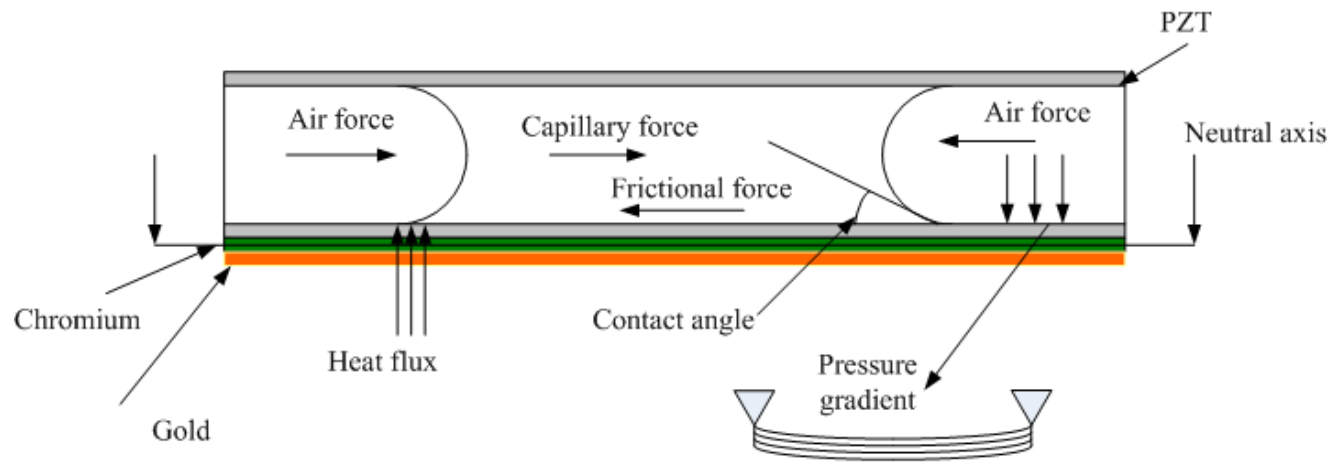

Membrane deflection

Fig. 1: Schematic of problem configuration in the MHE

Ti-W Heatears

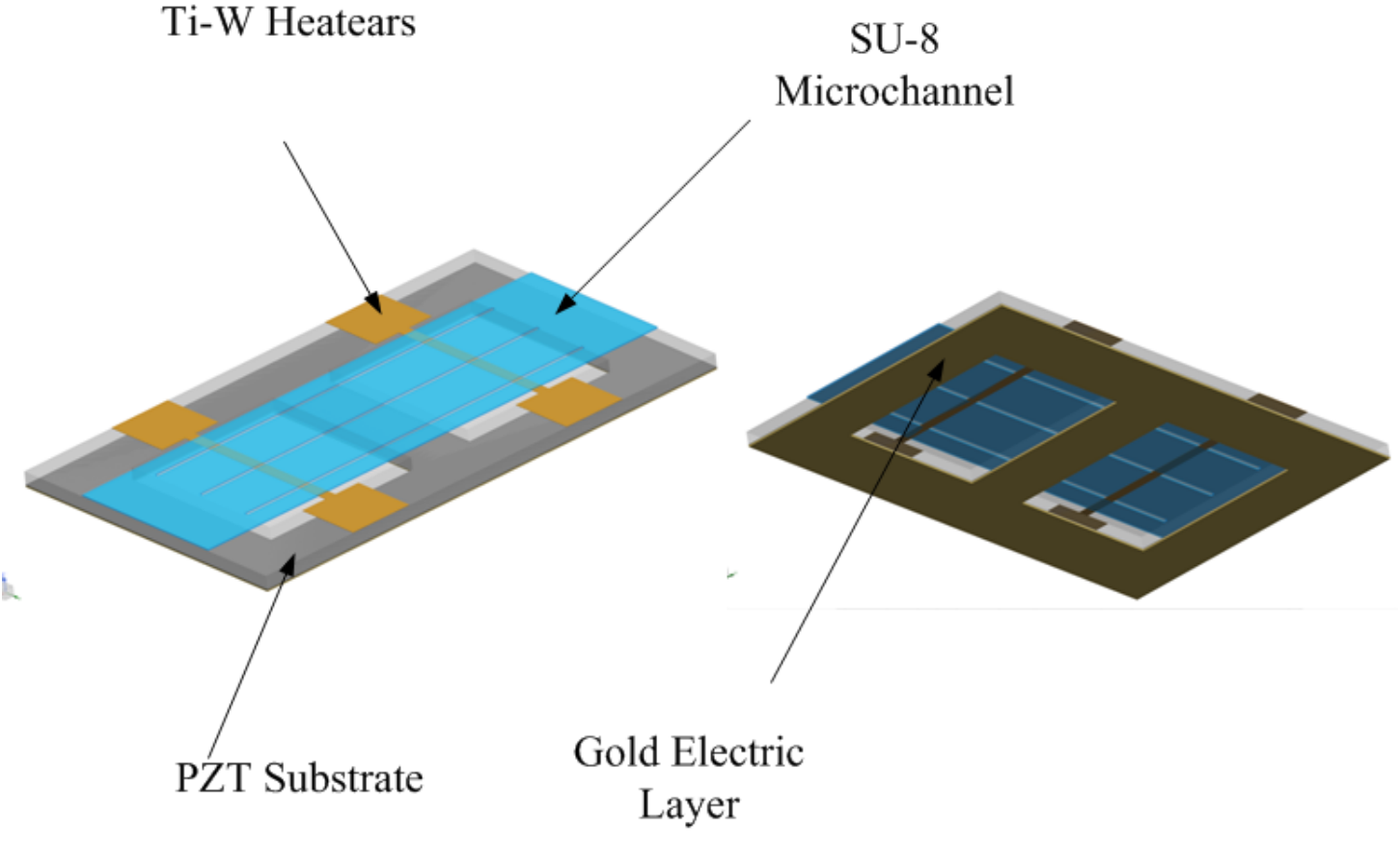

Fig. 2: Complete micro heat engine assembly 


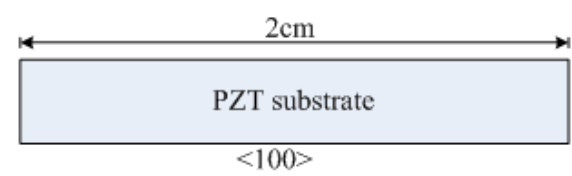

(a)

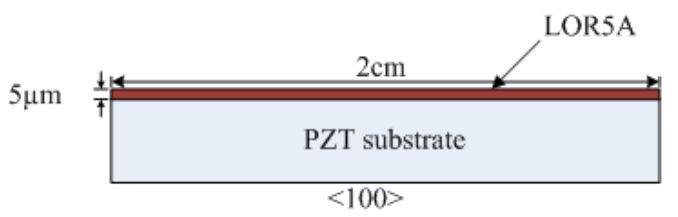

(b)

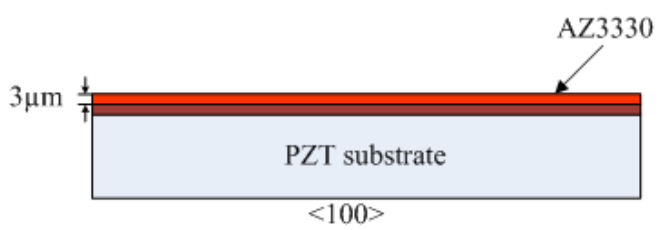

(c)

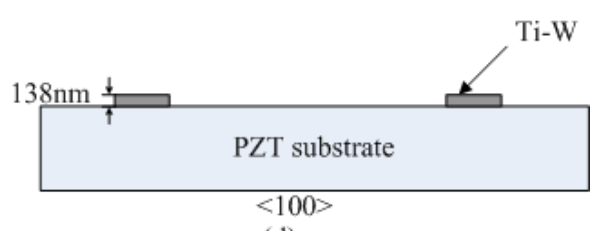

(d)

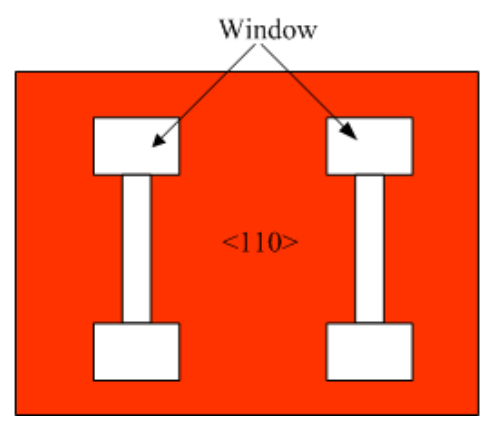

Fig. 3: Surface micromachining steps for fabrication of Ti-W microheaters using photolithography, sputtering and wet etching 


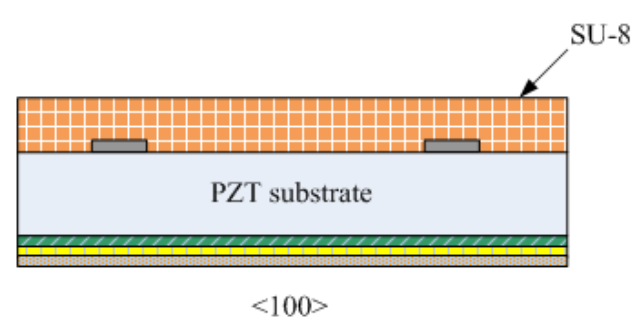

(i)

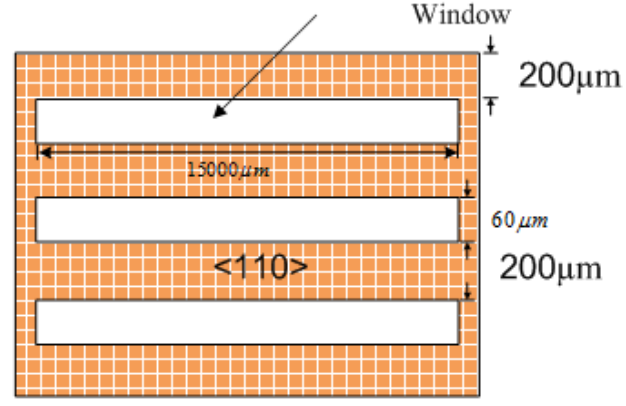

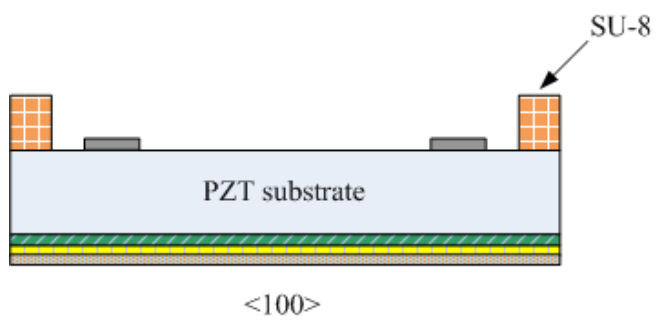

(j)

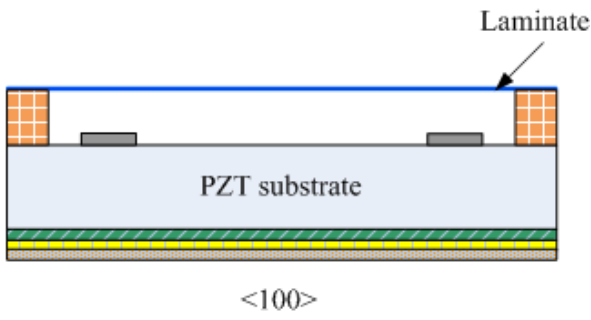

(k)

Fig. 4: Fabrication of SU-8 microchannels using photolithography and sealing of the microchannel using the Bungard dry film laminator

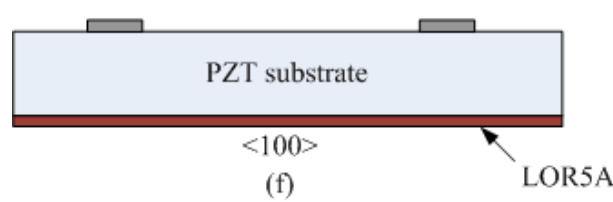

PZT substrate

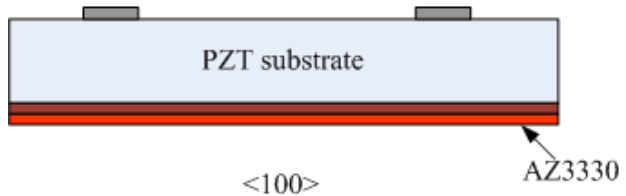

(g)

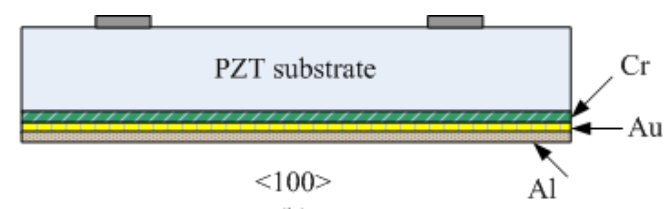

(h)

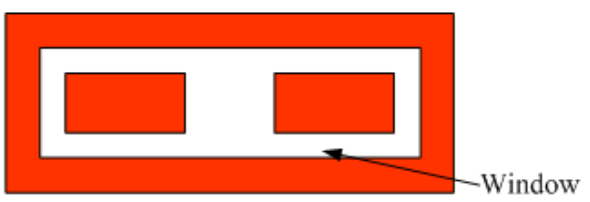

Fig. 5: Surface micromachining steps for back side of PZT substrate using photolithography, electron vacuum deposition, sputtering, and reactive ion etching 


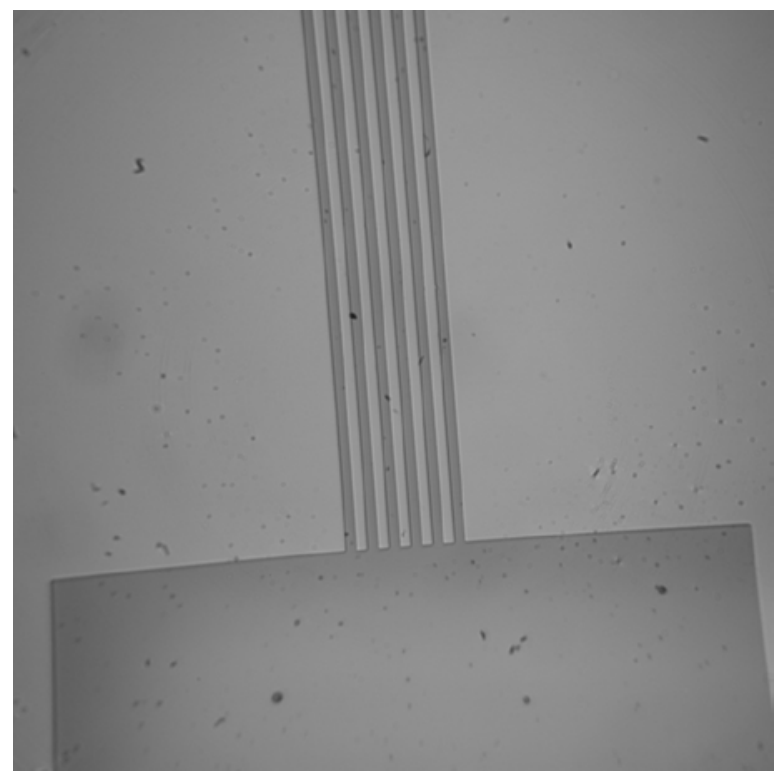

Fig. 6: Fabricated Ti-W microheaters

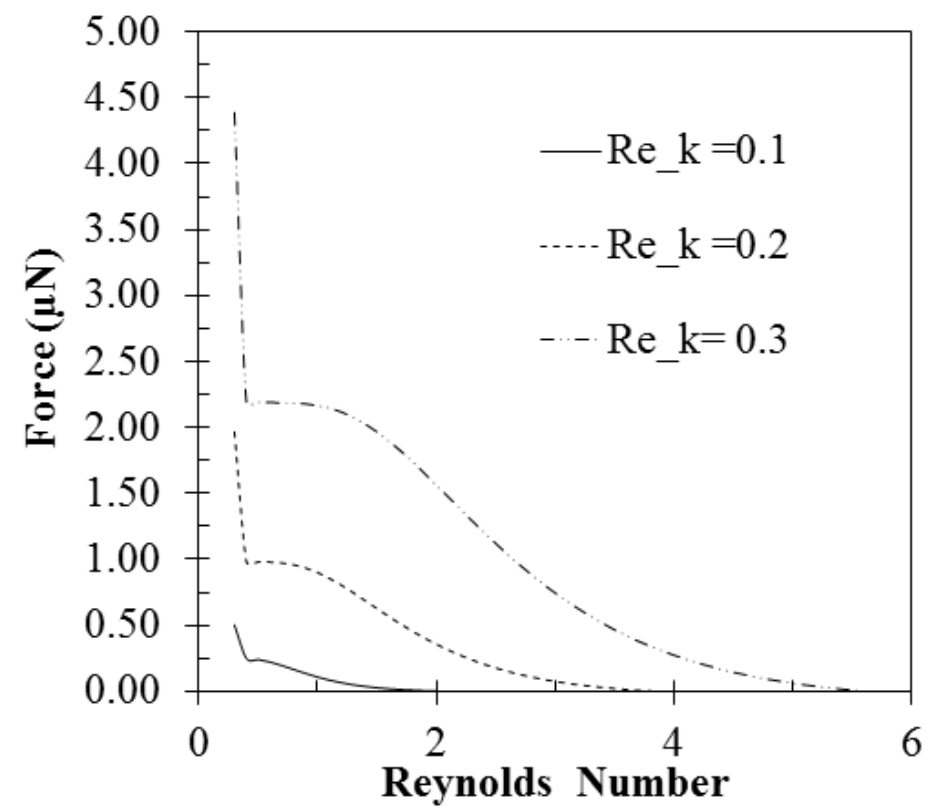

Fig. 7: Effect of local roughness Reynolds number on frictional force in a closed circular microchannel (16 $\mu \mathrm{m}$ closed microchannel) 


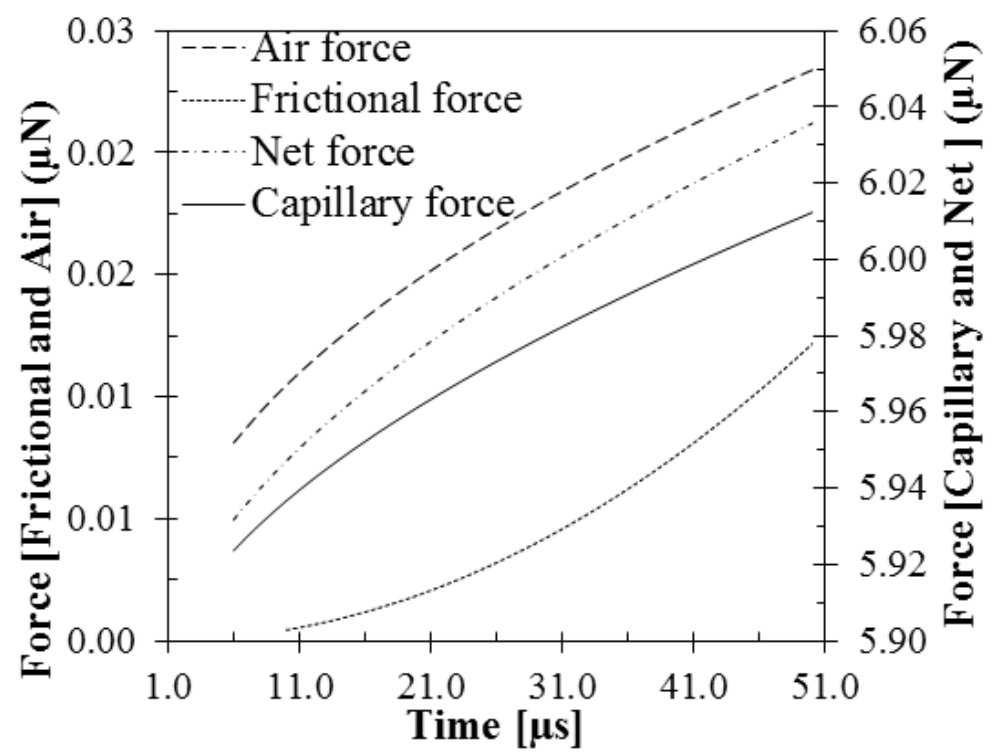

Fig. 8: Distribution of forces during a heating cycle of the MHE

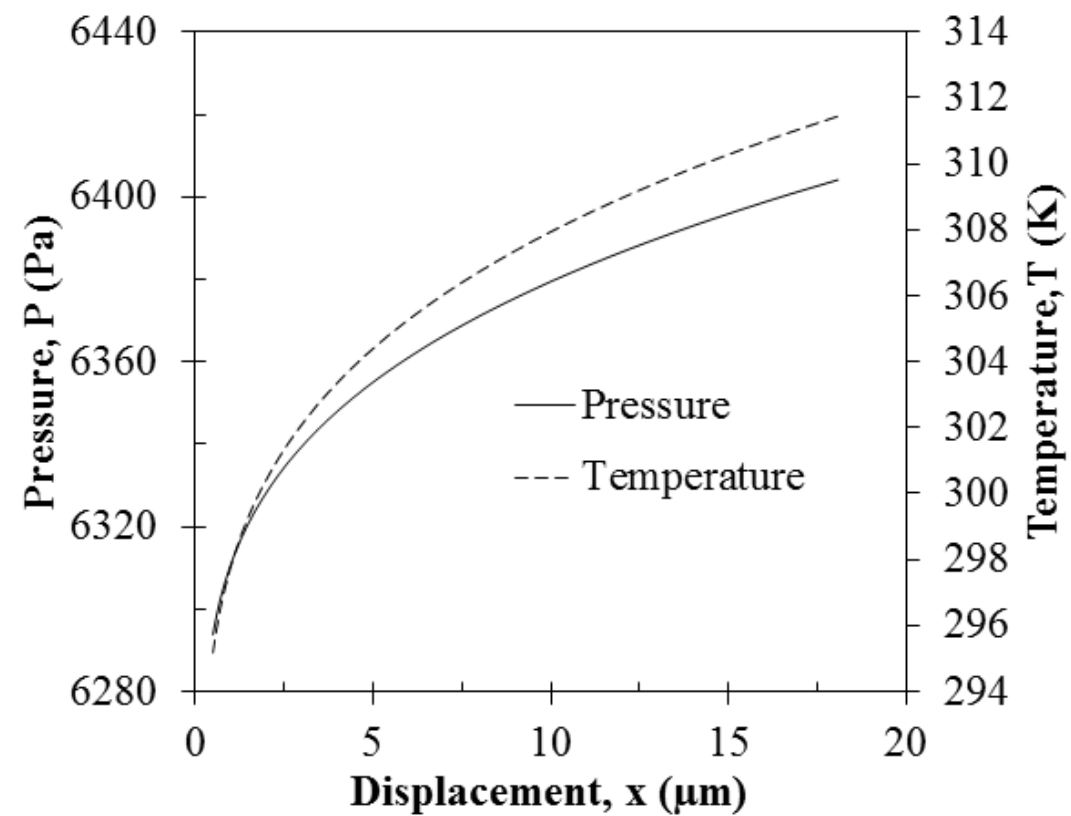

Fig. 9: Effects of droplet displacement on temperature and pressure in the MHE [rectangular cross section $(60 \times 60 \mu \mathrm{m})]$ 


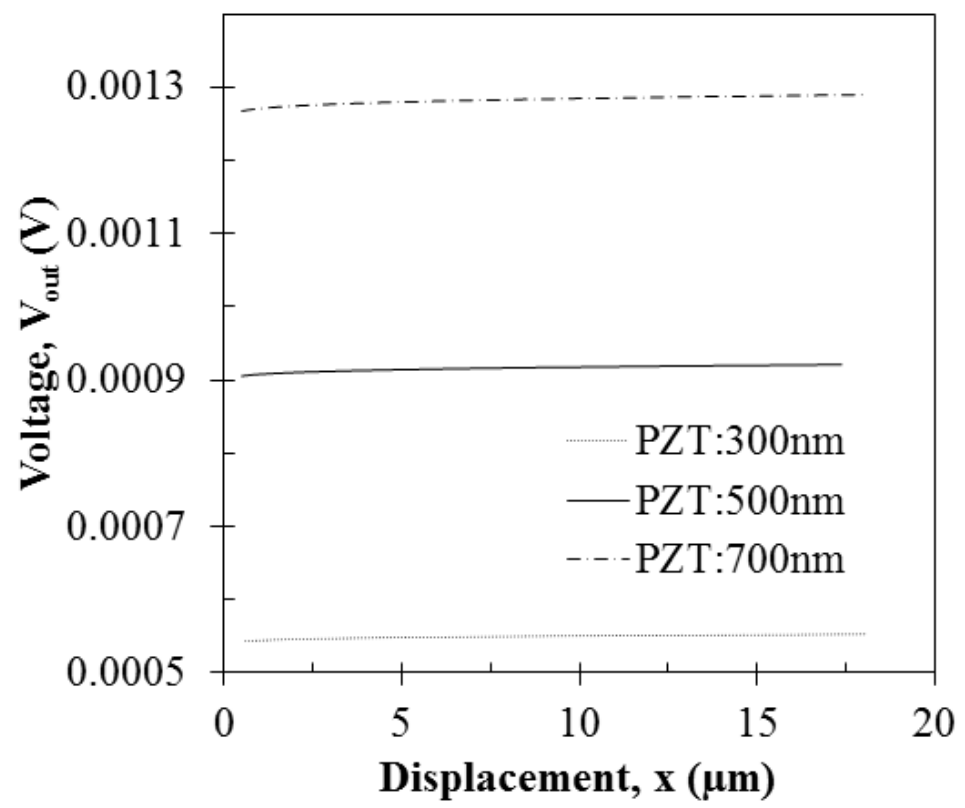

Fig. 10: Effect of displacement of the microdroplet on the voltage produced for different piezoelectric heights

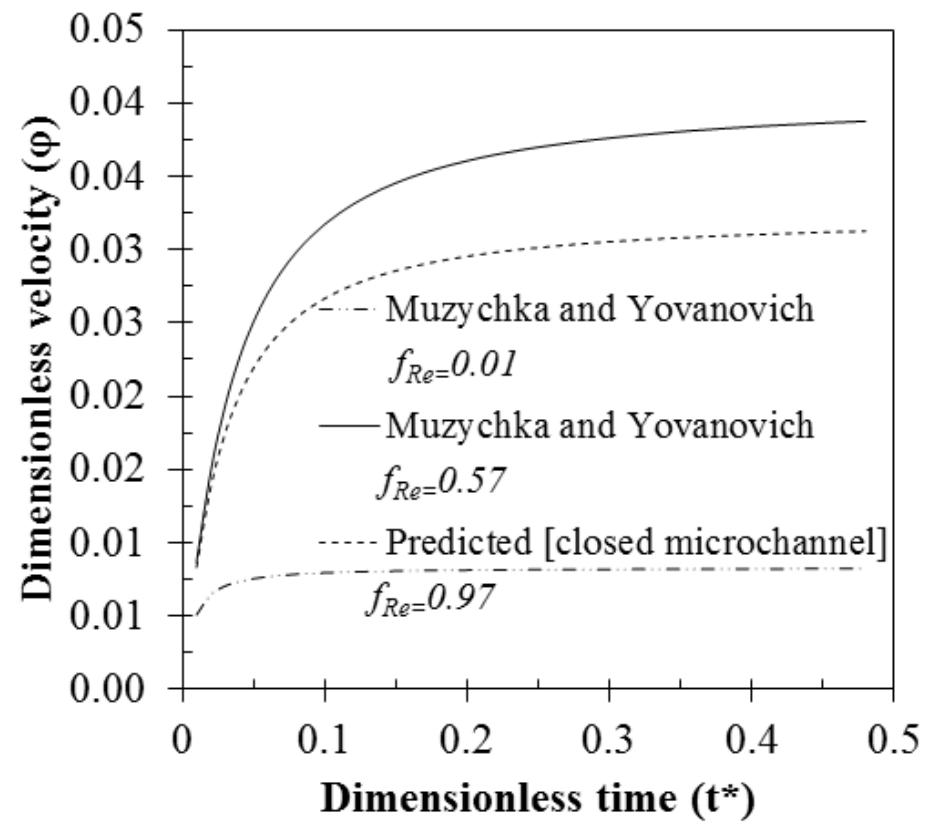

Fig.11: The effect of friction factor on dimensionless velocity for open and closed microchannels 


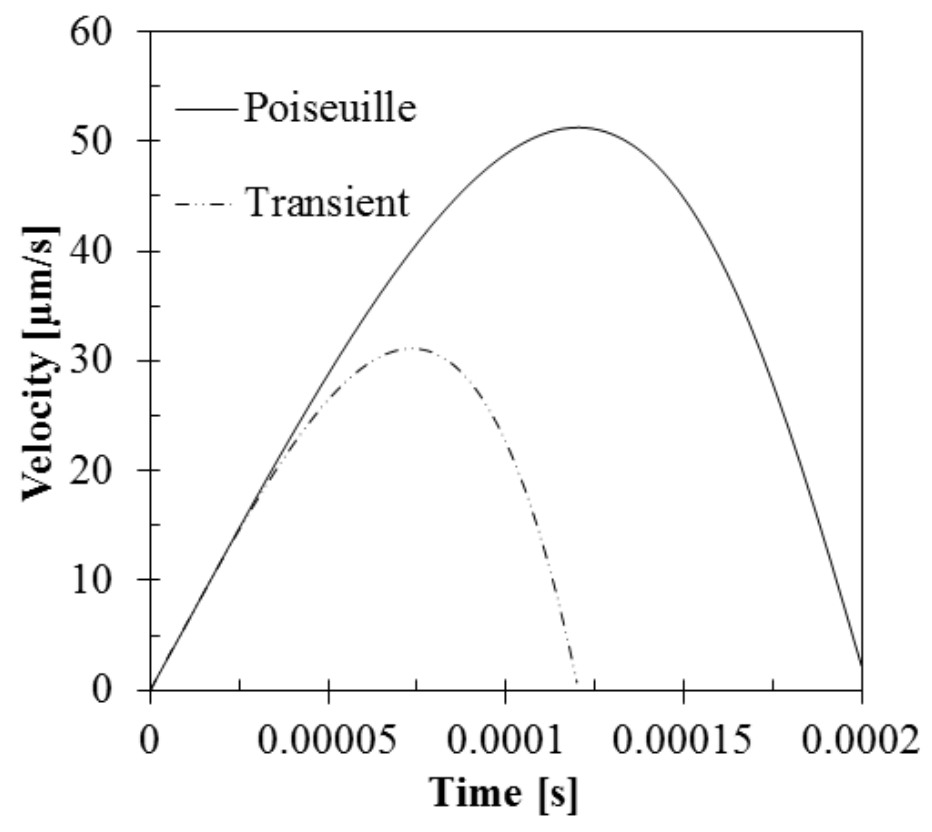

Fig.12: Comparison of the effects of the Poiseuille flow assumption and transient velocity in the MHE [rectangular cross section $(60 \times 60 \mu \mathrm{m})]$

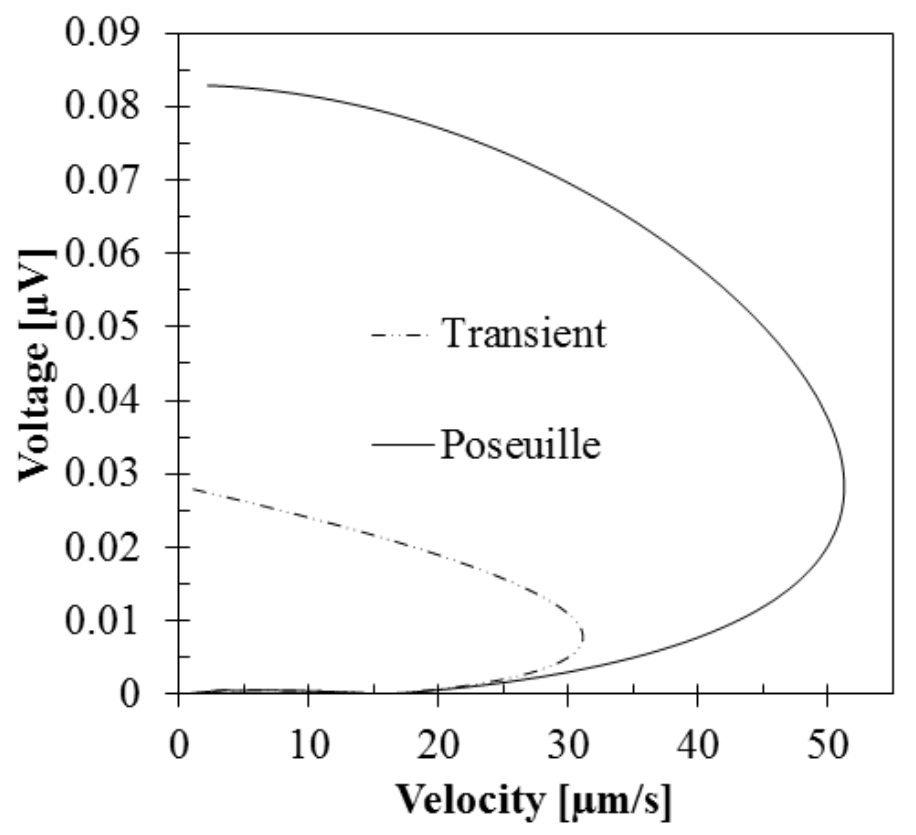

Fig.13: Comparison of the effects of the Poiseuille flow assumption and the transient voltage generated in the MHE [rectangular cross section $(60 \times 60 \mu \mathrm{m})$ ] 


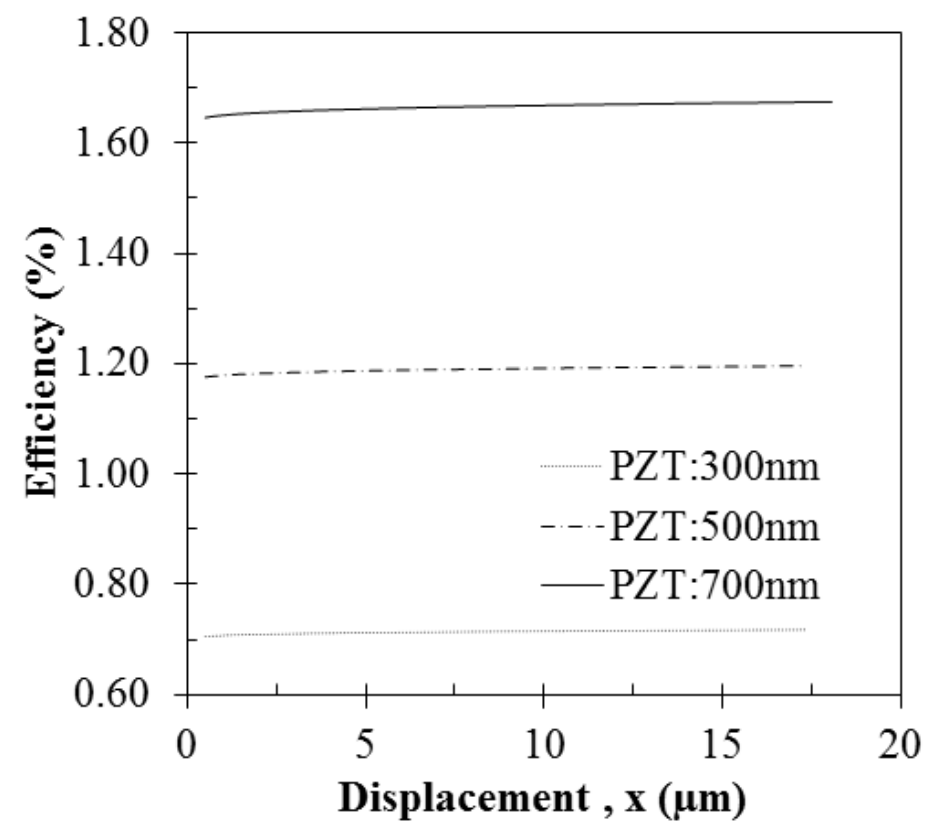

Fig.14: Effects of droplet displacement on the efficiency produced in a MHE for various heights of piezoelectric membranes

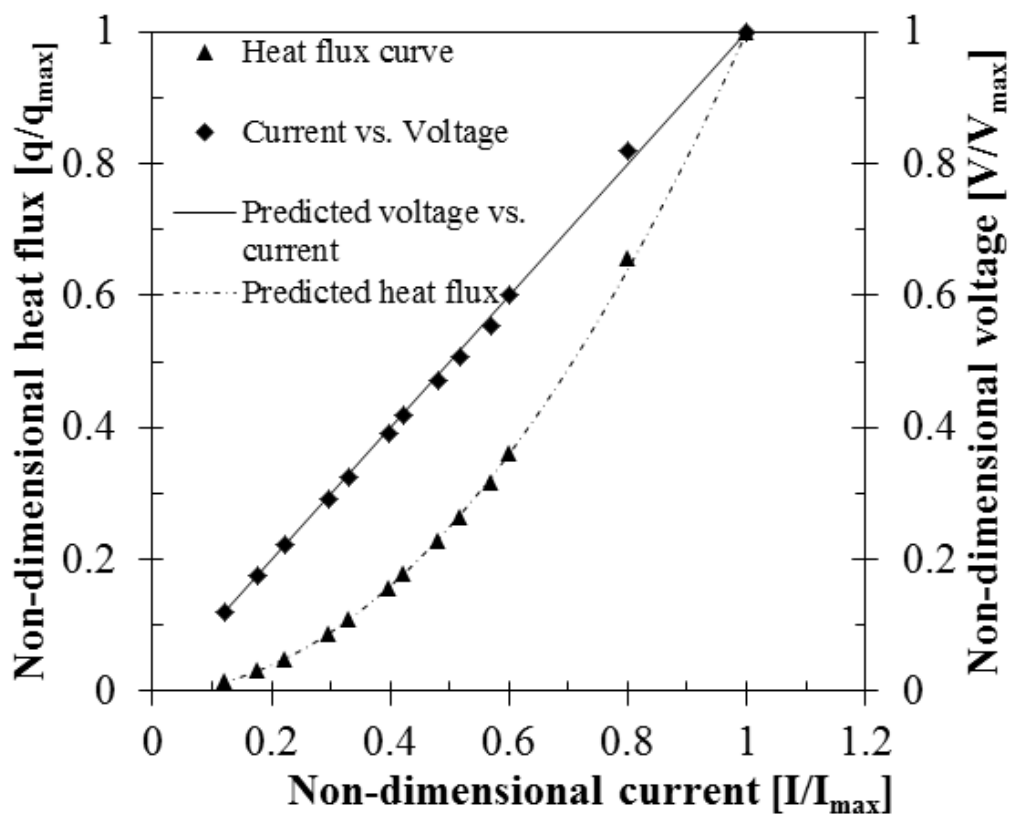

Fig.15: Comparison between experimental and analytical measurements of the heat flux and voltage supplied to the MHE 